\title{
Comment
}

\section{Comment on 'Shang S. 2012. Calculating actual crop evapotranspiration under soil water stress conditions with appropriate numerical methods and time step. Hydrological Processes 26: 3338-3343. DOI: 10.1002/hyp.8405'}

\author{
Soni Yatheendradas, ${ }^{1,2 *}$ Balachandrudu Narapusetty, ${ }^{2,3}$ Christa Peters-Lidard, ${ }^{2}$ \\ Christopher Funk ${ }^{4,5}$ and James Verdin ${ }^{5}$ \\ ${ }^{1}$ Earth System Science Interdisciplinary Center, University of Maryland, College Park, MD 20742, USA \\ ${ }^{2}$ Hydrological Sciences Laboratory, NASA Goddard Space Flight Center, Greenbelt, MD 20771, USA \\ ${ }^{3}$ Science Applications International Corporation, Beltsville, MD 20705, USA \\ ${ }^{4}$ Department of Geography, University of California, Santa Barbara, CA 93106, USA \\ ${ }^{5}$ Earth Resources Observation Systems (EROS) Data Center, USGS, Sioux Falls, SD 57198, USA
}

\begin{abstract}
:
A previous study analyzed errors in the numerical calculation of actual crop evapotranspiration $\left(\mathrm{ET}_{\mathrm{a}}\right)$ under soil water stress. Assuming no irrigation or precipitation, it constructed equations for $\mathrm{ET}_{\mathrm{a}}$ over limited soil-water ranges in a root zone drying out due to evapotranspiration. It then used a single crop-soil composite to provide recommendations about the appropriate usage of numerical methods under different values of the time step and the maximum crop evapotranspiration $\left(\mathrm{ET}_{\mathrm{c}}\right)$. This comment reformulates those $\mathrm{ET}_{\mathrm{a}}$ equations for applicability over the full range of soil water values, revealing a dependence of the relative error in numerical $\mathrm{ET}_{\mathrm{a}}$ on the initial soil water that was not seen in the previous study. It is shown that the recommendations based on a single crop-soil composite can be invalid for other crop-soil composites. Finally, a consideration of the numerical error in the time-cumulative value of $\mathrm{ET}_{\mathrm{a}}$ is discussed besides the existing consideration of that error over individual time steps as done in the previous study. This cumulative $\mathrm{ET}_{\mathrm{a}}$ is more relevant to the final crop yield. Published 2014. This article is a U.S. Government work and is in the public domain in the USA.
\end{abstract}

KEY WORDS numerical method; crop; evapotranspiration; water stress

Received 13 February 2013; Accepted 20 December 2013

\section{THE SHANG (2012) STUDY: ASSUMPTIONS, EQUATIONS AND RECOMMENDATIONS}

Shang (2012) is hereforth denoted in this comment article as $\mathrm{S} 12$, whereas this article itself is denoted as $\mathrm{YC}$ for Yatheendradas (et al.) comment. Besides the original assumptions for calculating the actual crop evapotranspiration $\left(\mathrm{ET}_{\mathrm{a}}\right.$ ) by Allen et al. (1998), S12 made important additional assumptions that are accordingly followed here as well:

1. Meteorological/atmospheric conditions were constant over multiple time steps (see Figure 3 by S12). This

\footnotetext{
*Correspondence to: Soni Yatheendradas, Hydrological Sciences Laboratory, NASA Goddard Space Flight Center, Greenbelt, MD 20771, USA. E-mail: soni.yatheendradas@nasa.gov
}

means that the standard reference crop evapotranspiration $\left(\mathrm{ET}_{\mathrm{o}}\right)$ from either grass or alfalfa was assumed constant. 2. Important source terms were neglected in the analytical and numerical formulations, where their inclusion may change the results and recommendations. One such term is the water input (irrigation or precipitation). This essentially slowly dried out the crop root zone because of evapotranspiration, starting from whichever considered instant in the crop phenology.

3. Another source term or key parameterization not considered but existing in reality and in practice is the time variation in the crop coefficient curve (Allen et al., 1998). Typically, this curve assumes a low constant initial value phase, followed by a linear increase during a crop development phase, then a 
maximum constant value over a mid-season phase, and finally a linear decrease till harvest in a late-season phase. The instantaneous maximum crop evapotranspiration $\left(\mathrm{ET}_{\mathrm{c}}\right)$ is obtained by multiplying $\mathrm{ET}_{\mathrm{o}}$ by this crop coefficient. So for a constant $\mathrm{ET}_{\mathrm{o}}$ from assumption 1 aforementioned, a constant $\mathrm{ET}_{\mathrm{c}}$ over multiple time steps implies a corresponding enforced constancy in the crop coefficient. Figures $1-3$ by $\mathrm{S} 12$ are obtained using this enforcement.

4. S12 neglected soil water flux through the bottom of root zone by assuming a 'deep groundwater level and in periods without heavy rain and irrigation'.

Following Allen et al. (1998), Equation (2) by S12 gave $\mathrm{ET}_{\mathrm{a}}$ using $\mathrm{ET}_{\mathrm{c}}$ and a water stress coefficient $\left(\mathrm{K}_{\mathrm{s}}\right)$ :

$$
\mathrm{ET}_{\mathrm{a}}=\mathrm{K}_{\mathrm{s}} \mathrm{ET}_{\mathrm{c}}
$$

Equation (3) by S12 gave this piecewise linear $\mathrm{K}_{\mathrm{s}}$ that increases with an increase in the soil water storage (W) from the wilting point $\left(\mathrm{W}_{\mathrm{p}}\right)$ to the critical soil water storage for soil water stress $\left(\mathrm{W}_{\mathrm{j}}\right)$ :

$$
\mathrm{K}_{\mathrm{s}}=\left\{\begin{array}{l}
0, \quad \mathrm{~W} \leq \mathrm{W}_{\mathrm{p}} \\
\left(\mathrm{W}-\mathrm{W}_{\mathrm{p}}\right) /\left(\mathrm{W}_{\mathrm{j}}-\mathrm{W}_{\mathrm{p}}\right), \mathrm{W}_{\mathrm{p}}<W<\mathrm{W}_{\mathrm{j}} \\
1, \quad \mathrm{~W} \geq \mathrm{W}_{\mathrm{j}}
\end{array}\right.
$$

Here, $\mathrm{W}_{\mathrm{j}}$ was given by Equation (4) by $\mathrm{S} 12$ as lying between $\mathrm{W}_{\mathrm{p}}$ and the soil water at field capacity $\left(\mathrm{W}_{\mathrm{f}}\right)$ :

$$
\mathrm{W}_{\mathrm{j}}=\mathrm{pW}_{\mathrm{p}}+(1-\mathrm{p}) \mathrm{W}_{\mathrm{f}}, 0<p<1
$$

where $p$ is the depletable fraction of root zone water before water stress, and Equation (5) by S12 showed p depending both on the crop type through a $\mathrm{p}_{\text {std }}$ term and on the $\mathrm{ET}_{\mathrm{c}}(\mathrm{mm} / \mathrm{day})$ :

$$
\mathrm{p}=\mathrm{p}_{\mathrm{std}}+0.04\left(5-\mathrm{ET}_{\mathrm{c}}\right)
$$

Finally, assuming that soil water stayed in the $\mathrm{W}_{\mathrm{p}}<\mathrm{W}<\mathrm{W}_{\mathrm{j}}$ range in Equation (2) earlier for a time step, Equation (8) by S12 gave the following analytical solution $\left(\mathrm{ET}_{\mathrm{b}}\right)$ of $\mathrm{ET}_{\mathrm{a}}$ :

$\mathrm{ET}_{\mathrm{b}}=\left(\mathrm{W}_{\mathrm{o}}-\mathrm{W}_{\mathrm{p}}\right)\left\{1-\mathrm{e}^{\left[-\frac{\overline{\mathrm{ET}_{\mathrm{c}}} \Delta t}{\mathrm{~W}_{\mathrm{j}}-\mathrm{W}_{\mathrm{p}}}\right]}\right\}, \mathrm{W}_{\mathrm{p}}<W<\mathrm{W}_{\mathrm{j}}$

where $\mathrm{W}_{\mathrm{o}}$ is the initial soil water storage, $\Delta \mathrm{t}$ is the time step, and $\overline{\mathrm{ET}}_{\mathrm{c}}$ is the $\mathrm{ET}_{\mathrm{c}}$ assumed constant (or 'representative') over the time step. Note that although $\mathrm{ET}_{\mathrm{c}}$ is a rate, its analytical solution $\mathrm{ET}_{\mathrm{b}}$ was formulated as a depth $(\mathrm{mm})$.

For the same $\mathrm{W}_{\mathrm{p}}<\mathrm{W}<\mathrm{W}_{\mathrm{j}}$ range, the Equations (9), (15) and (17) by $\mathrm{S} 12$ gave the following numerical solutions of the $\mathrm{ET}_{\mathrm{a}}$ depth (mm), denoted by $\mathrm{ET}_{\mathrm{ee}}, \mathrm{ET}_{\mathrm{me}}$ and $\mathrm{ET}_{\mathrm{H} 3}$ for the explicit Euler, the modified Euler and the Heun's thirdorder methods, respectively:

$$
\mathrm{ET}_{\mathrm{ee}}=\frac{\mathrm{W}_{\mathrm{o}}-\mathrm{W}_{\mathrm{p}}}{\mathrm{W}_{\mathrm{j}}-\mathrm{W}_{\mathrm{p}}} \overline{\mathrm{ET}}_{\mathrm{c}} \Delta \mathrm{t}, \quad \mathrm{W}_{\mathrm{p}}<\mathrm{W}<\mathrm{W}_{\mathrm{j}}
$$

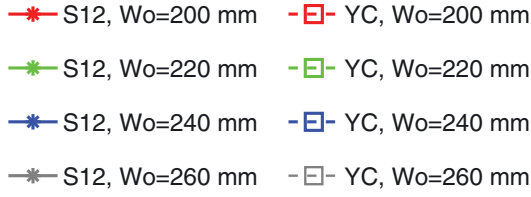

(a) $p_{\text {std }}=0.55$

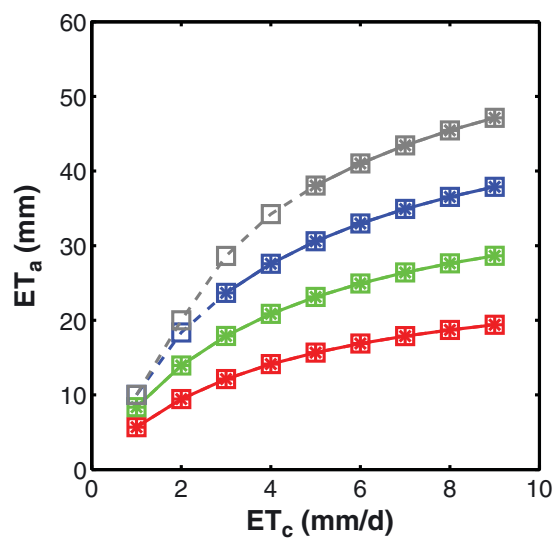

(b) $\mathrm{p}_{\mathrm{std}}=0.8$

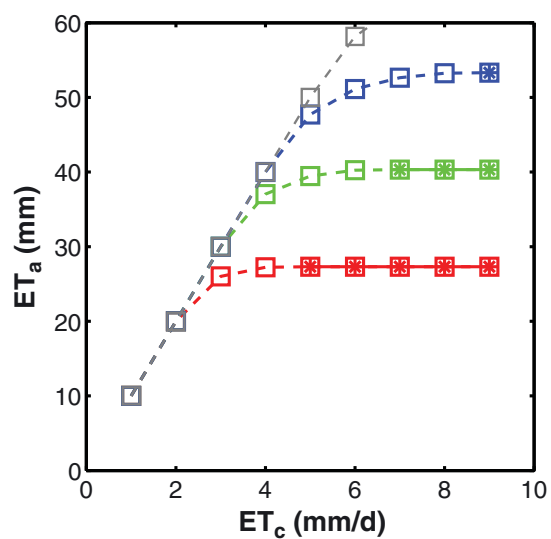

Figure 1. Analytical $\mathrm{ET}_{\mathrm{a}}$ (i.e. $\mathrm{ET}_{\mathrm{b}}$ ) for different values of $\mathrm{ET}_{\mathrm{c}}, \mathrm{W}_{\mathrm{o}}$ and $\mathrm{p}_{\mathrm{std}}$. In the legend, $\mathrm{S} 12$ and $\mathrm{YC}$, respectively denote usage of equations from Shang (2012) and this comment article 

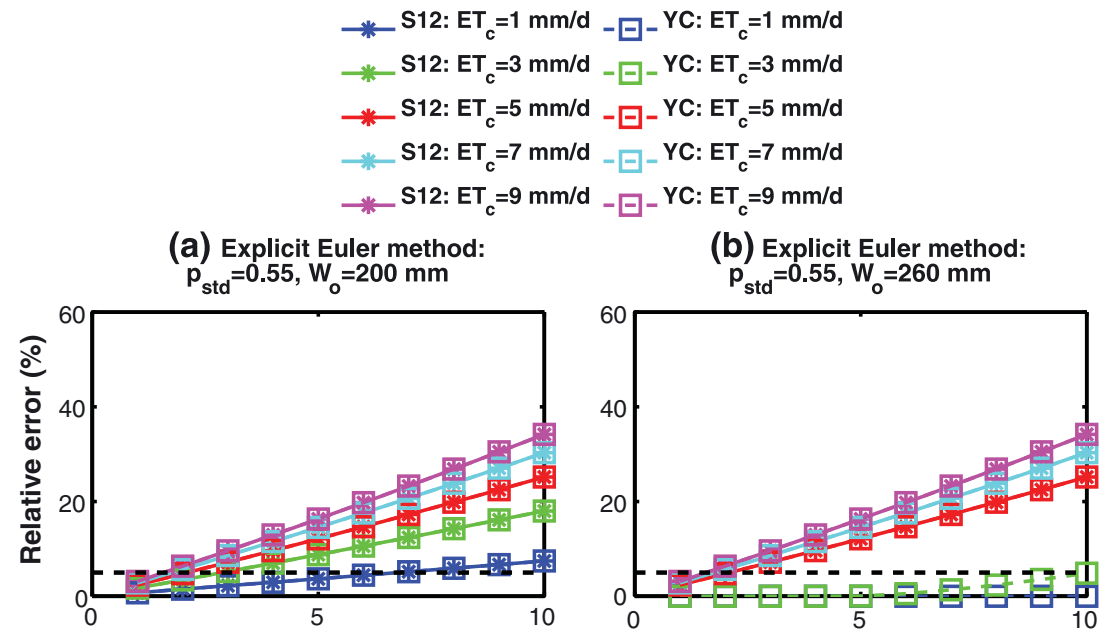

(c) Explicit Euler method:

(d) Explicit Euler method: $p_{s t d}=0.55, w_{f} \& w_{p}$ halved, $w_{o}=260 / 2 \mathrm{~mm} \quad p_{s t d}=0.8, w_{f} \& w_{p}$ halved, $w_{o}=200 / 2 \mathrm{~mm}$
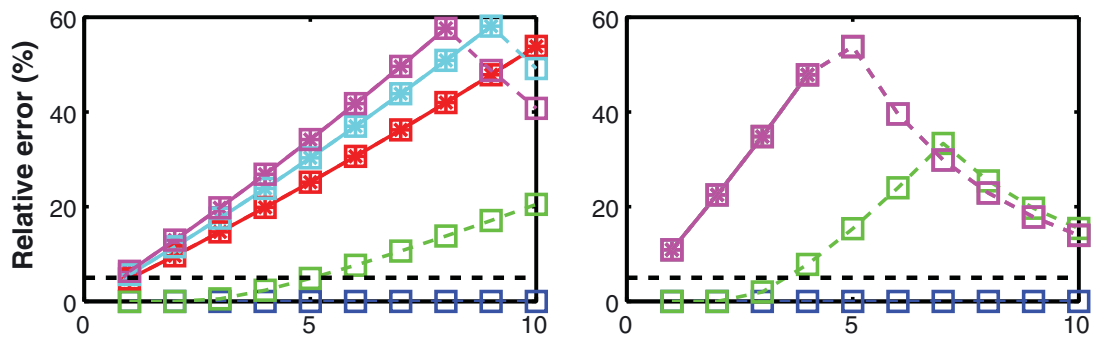

(e) Modified Euler method: $p_{s t d}=0.8, w_{f} \& w_{p}$ halved, $w_{o}=200 / 2 \mathrm{~mm}$

(f) Heun's 3rd-order method:

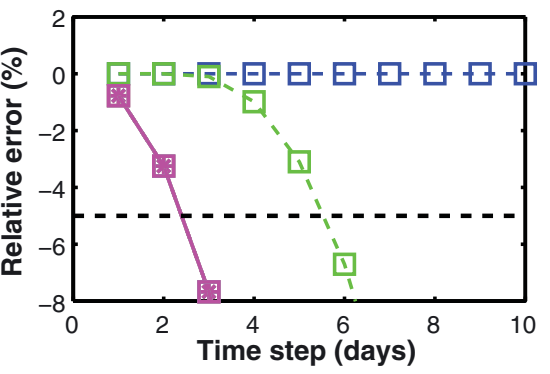
$p_{\text {std }}=0.8, w_{o}=200 \mathrm{~mm}$

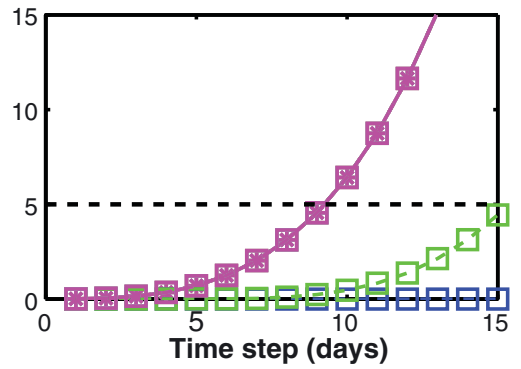

Figure 2. Relative error in $\mathrm{ET}_{\mathrm{a}}$ for some numerical methods, crop-soil composites, initial conditions and $\mathrm{ET}_{\mathrm{c}}$ values. In the legend, $\mathrm{S} 12$ and $\mathrm{YC}$, respectively, denote the usage of equations from Shang (2012) and this comment article. Horizontal dashed line is the relative error threshold at 5\% (or $-5 \%$ as relevant)

$$
\begin{aligned}
\mathrm{ET}_{\mathrm{me}}= & \frac{\mathrm{W}_{\mathrm{o}}-\mathrm{W}_{\mathrm{p}}}{\mathrm{W}_{\mathrm{j}}-\mathrm{W}_{\mathrm{p}}} \overline{\mathrm{ET}}_{\mathrm{c}} \Delta \mathrm{t}\left(1-\frac{1}{2} \frac{\overline{\mathrm{ET}}_{\mathrm{c}} \Delta \mathrm{t}}{\mathrm{W}_{\mathrm{j}}-\mathrm{W}_{\mathrm{p}}}\right), \mathrm{W}_{\mathrm{p}}<\mathrm{W}<\mathrm{W}_{\mathrm{j}} \\
\mathrm{ET}_{\mathrm{H} 3}= & \frac{\mathrm{W}_{\mathrm{o}}-\mathrm{W}_{\mathrm{p}}}{\mathrm{W}_{\mathrm{j}}-\mathrm{W}_{\mathrm{p}}} \overline{\mathrm{ET}}_{\mathrm{c}} \Delta \mathrm{t}\left[1-\frac{1}{2} \frac{\overline{\mathrm{ET}_{\mathrm{c}} \Delta \mathrm{t}}}{\mathrm{W}_{\mathrm{j}}-\mathrm{W}_{\mathrm{p}}}+\frac{1}{6}\left(\frac{\overline{\mathrm{ET}_{\mathrm{c}} \Delta \mathrm{t}}}{\mathrm{W}_{\mathrm{j}}-\mathrm{W}_{\mathrm{p}}}\right)^{2}\right], \\
& \mathrm{W}_{\mathrm{p}}<\mathrm{W}<\mathrm{W}_{\mathrm{j}}
\end{aligned}
$$

S12 further used analytical Equation (5) in the previous texts as a benchmark to calculate the relative errors in the numerical $\mathrm{ET}_{\mathrm{a}}$ from these Equations (6)-(8). Accordingly, S12 preferred less complex numerical methods for computational efficiency in making the following recommendations on their selection for calculating a satisfactorily accurate numerical $\mathrm{ET}_{\mathrm{a}}$ :

A. If the time step is 1 day (d) and $\mathrm{ET}_{\mathrm{c}}$ is any value, then use explicit Euler, else,

B. if the time step is up to 2 days and $\mathrm{ET}_{\mathrm{c}}$ is below $5 \mathrm{~mm} / \mathrm{day}$, then use explicit Euler, else,

C. if the time step is up to 1 week and $\mathrm{ET}_{\mathrm{c}}$ is any value, then use midpoint/modified Euler, else,

D. if the time step is up to 10 days and $\mathrm{ET}_{\mathrm{c}}$ is below $5 \mathrm{~mm} /$ day, then use midpoint/modified Euler, else,

E. if the time step is up to 1 week and $\mathrm{ET}_{\mathrm{c}}$ is any value, then use Heun's $3^{\text {rd }}$-order method. 


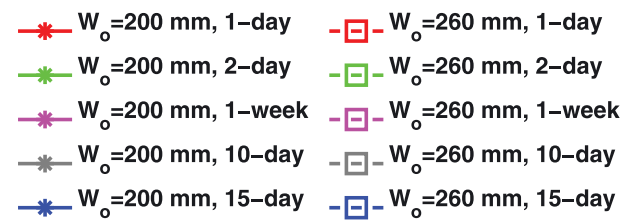

(a) Explicit Euler, $\mathrm{ET}_{\mathrm{c}}=5 \mathrm{~mm} / \mathrm{d}$

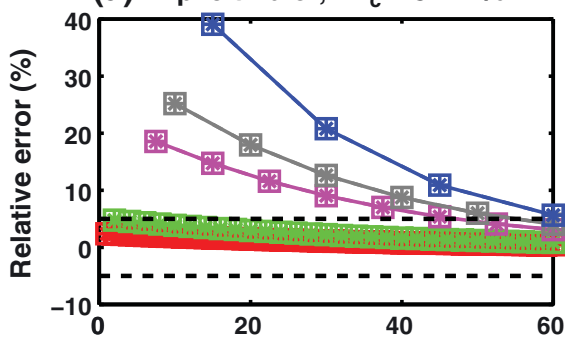

(c) Explicit Euler, $\mathrm{ET}_{\mathrm{c}}=1->9 \mathrm{~mm} / \mathrm{d}$

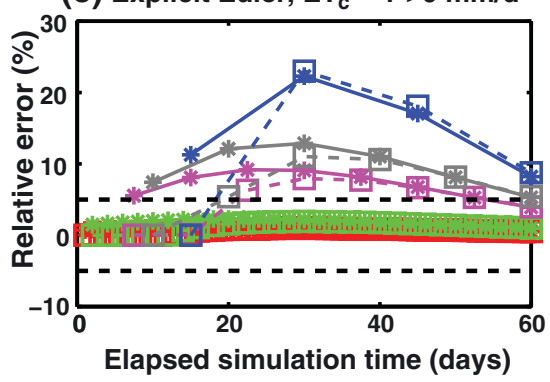

(b) Explicit Euler, $\mathrm{ET}_{\mathrm{c}}=9 \mathrm{~mm} / \mathrm{d}$

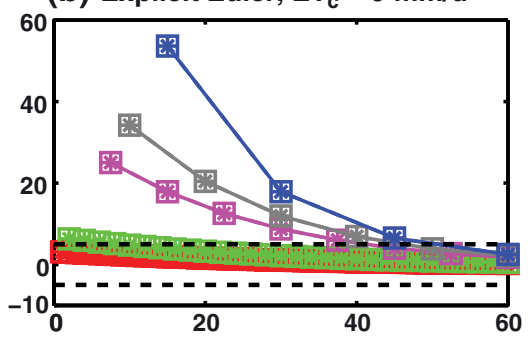

(d) Explicit Euler, $\mathrm{ET}_{\mathrm{c}}=9->1 \mathrm{~mm} / \mathrm{d}$

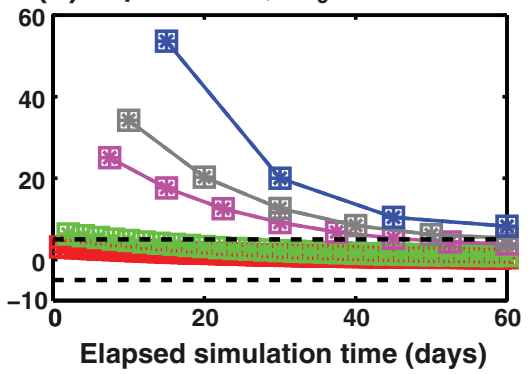

Figure 3. Relative error in cumulated $\mathrm{ET}_{\mathrm{a}}$ of S12's crop-soil composite using the reformulated explicit Euler method for different ETc trends, initial conditions (Wo) and time step. Horizontal dashed lines are the relative error thresholds at $\pm 5 \%$

These recommendations were obviously made with practical applicability in mind. Hence, it is worth noting that following them for computational efficiency while attempting a realistic case of a non-constant $\mathrm{ET}_{\mathrm{c}}$ over multiple time steps (i.e. by relaxing assumption 3 earlier) can mean continuously changing the numerical method during the simulation. For example, for a fixed time step of 2 days, a change in $\mathrm{ET}_{\mathrm{c}}$ from $4 \mathrm{~mm} /$ day at a time step to $6 \mathrm{~mm} /$ day at the next would correspond to a change in the numerical method from the explicit Euler to the midpoint/modified Euler.

\section{REFORMULATING THE S12 EQUATIONS: EFFECT ON RESULTS AND RECOMMENDATIONS}

Figure 1 by $\mathrm{S} 12$ showed the analytical $\mathrm{ET}_{\mathrm{b}}$ after a 10-day time step over a range of values for the $\mathrm{ET}_{\mathrm{c}}(1$ to $9 \mathrm{~mm} /$ day) and initial soil water ( $\mathrm{W}_{\mathrm{o}}$ from 200 to $260 \mathrm{~mm}$ ). These ranges and the properties for crop $\left(\mathrm{p}_{\text {std }}=0.55\right)$ and soil $\left(\mathrm{W}_{\mathrm{p}}=158 \mathrm{~mm}, \mathrm{~W}_{\mathrm{j}}=396 \mathrm{~mm}\right)$ are characteristic of their study site in North China. However, some combinations of $\mathrm{ET}_{\mathrm{c}}$ and $\mathrm{W}_{\mathrm{o}}$ actually move $\mathrm{W}_{\mathrm{o}}$ out of the assumed $\mathrm{W}_{\mathrm{p}}<\mathrm{W}<\mathrm{W}_{\mathrm{j}}$ range and into the $\mathrm{W}>\mathrm{W}_{\mathrm{j}}$ range. For example, an $\mathrm{ET}_{\mathrm{c}}$ of $1 \mathrm{~mm} /$ day gives a $\mathrm{W}_{\mathrm{j}}$ of around $227 \mathrm{~mm}$ using Equations (3) and (4) earlier, compared with which a $\mathrm{W}_{\mathrm{o}}$ of $260 \mathrm{~mm}$ is greater and so outside the $\mathrm{W}_{\mathrm{p}}<\mathrm{W}<\mathrm{W}_{\mathrm{j}}$ range. Such combinations of $\mathrm{ET}_{\mathrm{c}}$ and $\mathrm{W}_{\mathrm{o}}$ are omitted in Figure 1 by $\mathrm{S} 12$ and also in Figure 1a here wherein some asterisks derived using Equation (5) earlier are conspicuously absent at some square marker locations (these square markers are based on a reformulated $\mathrm{ET}_{\mathrm{b}}$ to be presented further in the succeeding texts). These combinations of $\mathrm{ET}_{\mathrm{c}}$ and $\mathrm{W}_{\mathrm{o}}$ having $\mathrm{W}_{\mathrm{o}}>\mathrm{W}_{\mathrm{j}}$ tend to occur on the higher $\mathrm{W}_{\mathrm{o}}$ curves at lower $\mathrm{ET}_{\mathrm{c}}$ values. Note that at higher $\mathrm{ET}_{\mathrm{c}}$ values on the same $\mathrm{W}_{\mathrm{o}}$ curves, $\mathrm{W}_{\mathrm{p}}<\mathrm{W}_{\mathrm{o}}<\mathrm{W}_{\mathrm{j}}$ happens because of Equations (3) and (4) earlier that result in a $\mathrm{W}_{\mathrm{j}}$ that increases with increasing $\mathrm{ET}_{\mathrm{c}}$.

For crop or soil properties different from the specific values considered by $\mathrm{S} 12$, such missing $\mathrm{ET}_{\mathrm{b}}$ values due to the $\mathrm{W}_{\mathrm{p}}<\mathrm{W}<\mathrm{W}_{\mathrm{j}}$ range constraint can occur for a significantly large number of combinations of $\mathrm{ET}_{\mathrm{c}}$ and $\mathrm{W}_{\mathrm{o}}$. For example, see asterisks absent at more than half of the square marker locations in Figure $1 \mathrm{~b}$ here, wherein the crop $\mathrm{p}_{\text {std }}$ value is now a higher-end value of 0.8 (Allen et al., 1998).

Analytical and numerical formulations of $\mathrm{ET}_{\mathrm{a}}$ specific to limited soil water ranges or not accounting for transition between such ranges would be limited in their applicability. For example, a formulation valid for soil 
water in the $\mathrm{W} \geq \mathrm{W}_{\mathrm{j}}$ range can be applied only if both $\mathrm{W}_{\mathrm{o}}$ and the soil water at the end of a time step are in that range. Avoiding this limited applicability requires inclusion in the formulations of the transition between ranges by soil water during a time step, for example, from the $\mathrm{W} \geq \mathrm{W}_{\mathrm{j}}$ range to the $\mathrm{W}_{\mathrm{p}}<\mathrm{W}<\mathrm{W}_{\mathrm{j}}$ range. Also, the $\mathrm{ET}_{\mathrm{b}}$ calculated using Equation (5) earlier for $\mathrm{a} \mathrm{W}_{\mathrm{o}}$ in the $\mathrm{W} \geq \mathrm{W}_{\mathrm{j}}$ range can be overbiased near $\mathrm{ET}_{\mathrm{c}}-\mathrm{W}_{\mathrm{o}}$ combinations where such transition occurs. As a

$$
\Delta \mathrm{t}_{1}=\left(\mathrm{W}_{\mathrm{o}}-\mathrm{W}_{\mathrm{j}}\right) / \overline{\mathrm{ET}}_{\mathrm{c}}, \quad \mathrm{W}_{\mathrm{o}} \geq \mathrm{W}_{\mathrm{j}}
$$

Note that soil water hitting the lower threshold $\mathrm{W}_{\mathrm{p}}$ during a time step is handled by enforcing this $\mathrm{W}_{\mathrm{p}}$ constraint using 'min' functions.

Applying this time step and $\mathrm{ET}_{\mathrm{a}}$ splitting and the $\mathrm{W}_{\mathrm{p}}$ constraint gives the following generally applicable analytical solution ( $\mathrm{ET}_{\mathrm{b}, \mathrm{C}}$ in $\mathrm{mm}$ ) of $\mathrm{ET}_{\mathrm{a}}$ instead of the Equation (5) earlier by $\mathrm{S} 12$ that had a $\mathrm{W}_{\mathrm{p}}<\mathrm{W}<\mathrm{W}_{\mathrm{j}}$ applicability only:

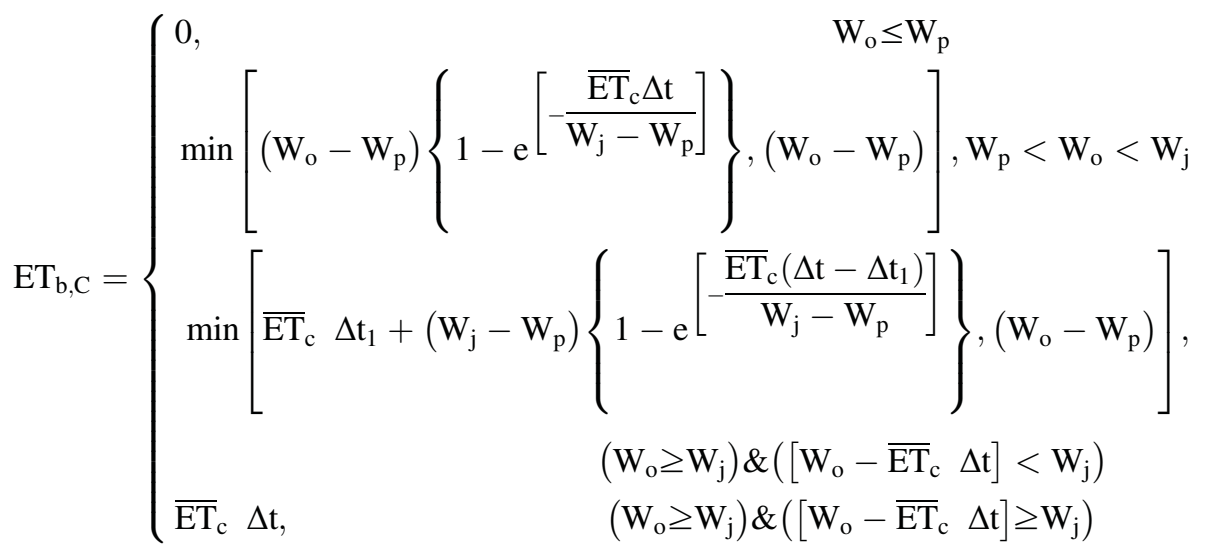

benchmark to calculate the relative error in numerical $\mathrm{ET}_{\mathrm{a}}$, accurate $\mathrm{ET}_{\mathrm{b}}$ is important. Hence, the analytical and numerical $\mathrm{S} 12$ equations are reformulated in the succeeding texts to avoid the aforementioned applicability constraints.

For a time step over which the soil water is above $\mathrm{W}_{\mathrm{j}}$ throughout, the $\mathrm{ET}_{\mathrm{a}}$ is constant at $\mathrm{ET}_{\mathrm{c}}$. For a time step that starts and ends with soil water values above and below $\mathrm{W}_{\mathrm{j}}$, respectively, the simpler $\mathrm{ET}_{\mathrm{a}}$ equations due to the $\mathrm{S} 12$ assumptions enable splitting the $\mathrm{ET}_{\mathrm{a}}$ into two terms. The initial term's corresponding portion of that time step when soil water is above $\mathrm{W}_{\mathrm{j}}$ is:
These $\mathrm{ET}_{\mathrm{b}, \mathrm{c}}$ values are the ones mentioned further earlier as being plotted in Figure 1 here using square markers. When $\mathrm{W}_{\mathrm{p}}<\mathrm{W}<\mathrm{W}_{\mathrm{j}}$ over a time step, they coincide with asterisk markers derived using Equation (5) earlier by $\mathrm{S} 12$.

Similarly, the following are the numerical solutions of $\mathrm{ET}_{\mathrm{a}}$ in millimetre (denoted by $\mathrm{ET}_{\mathrm{ee}, \mathrm{C}}, \mathrm{ET}_{\mathrm{me}, \mathrm{C}}$ and $\mathrm{ET}_{\mathrm{H} 3}$, $\mathrm{C}$ when using the explicit Euler, the modified Euler method and the Heun's third-order methods, respectively), instead of the Equations (6-8) earlier by S12 that had a $\mathrm{W}_{\mathrm{p}}<\mathrm{W}<\mathrm{Wj}$ applicability only:

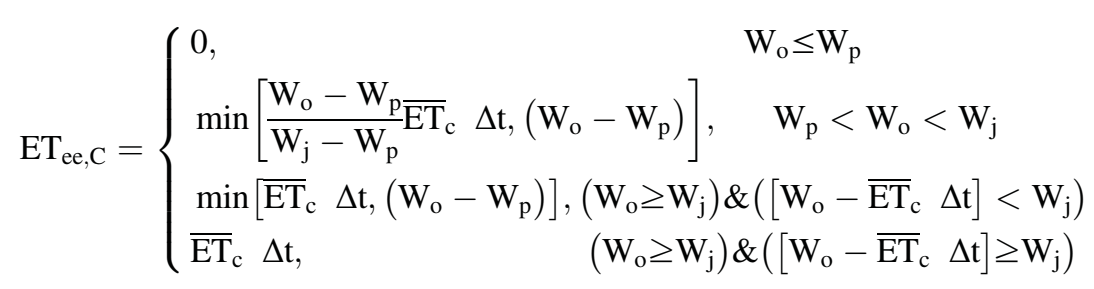




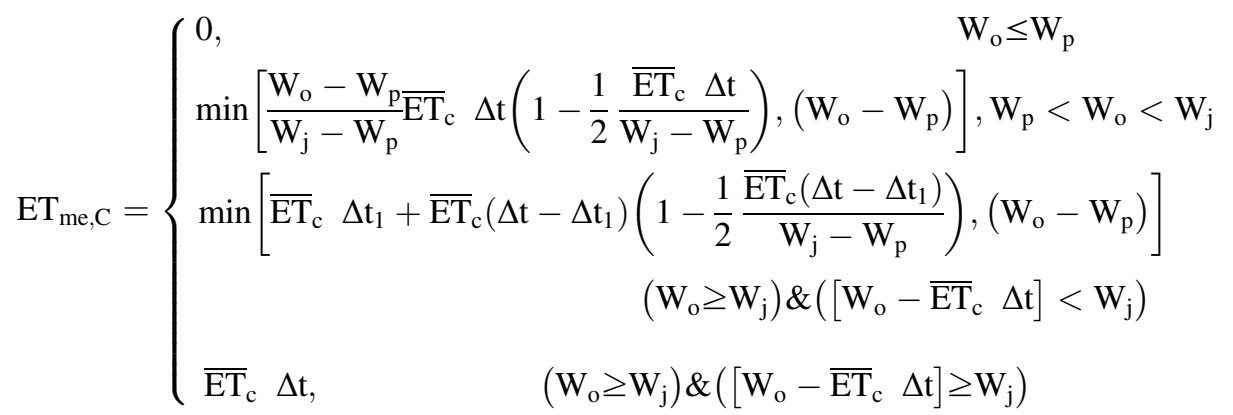

$$
\begin{aligned}
& \mathrm{ET}_{\mathrm{H} 3, \mathrm{C}}=\left\{\begin{array}{c}
\min \left[\frac{\mathrm{W}_{\mathrm{o}}-\mathrm{W}_{\mathrm{p}} \overline{\mathrm{W}}_{\mathrm{o}} \leq \mathrm{W}_{\mathrm{p}}}{\mathrm{W}_{\mathrm{j}}-\mathrm{W}_{\mathrm{p}}} \Delta \mathrm{t}\left(1-\frac{1}{2} \frac{\overline{\mathrm{ET}}_{\mathrm{c}} \Delta \mathrm{t}}{\mathrm{W}_{\mathrm{j}}-\mathrm{W}_{\mathrm{p}}}+\frac{1}{6}\left(\frac{\overline{\mathrm{ET}}_{\mathrm{c}} \Delta \mathrm{t}}{\mathrm{W}_{\mathrm{j}}-\mathrm{W}_{\mathrm{p}}}\right)^{2}\right),\left(\mathrm{W}_{\mathrm{o}}-\mathrm{W}_{\mathrm{p}}\right)\right], \\
\min \left[\overline{\mathrm{ET}}_{\mathrm{c}} \Delta \mathrm{t}_{1}+\overline{\mathrm{ET}}_{\mathrm{c}}\left(\Delta \mathrm{t}-\Delta \mathrm{t}_{\mathrm{l}}\right)\left(1-\frac{1}{2} \frac{\mathrm{W}_{\mathrm{p}}<\mathrm{W}_{\mathrm{o}}<\mathrm{W}_{\mathrm{j}}\left(\Delta \mathrm{t}-\Delta \mathrm{t}_{1}\right)}{\mathrm{W}_{\mathrm{j}}-\mathrm{W}_{\mathrm{p}}}+\frac{1}{6}\left(\frac{\overline{\mathrm{ET}}_{\mathrm{c}}\left(\Delta \mathrm{t}-\Delta \mathrm{t}_{1}\right)}{\mathrm{W}_{\mathrm{j}}-\mathrm{W}_{\mathrm{p}}}\right)^{2}\right),\left(\mathrm{W}_{\mathrm{o}}-\mathrm{W}_{\mathrm{p}}\right)\right], \\
\left(\mathrm{W}_{\mathrm{o}} \geq \mathrm{W}_{\mathrm{j}}\right) \&\left(\left[\mathrm{~W}_{\mathrm{o}}-\overline{\mathrm{ET}}_{\mathrm{c}} \Delta \mathrm{t}\right]<\mathrm{W}_{\mathrm{j}}\right) \\
\overline{\mathrm{ET}}_{\mathrm{c}} \Delta \mathrm{t}, \quad\left(\mathrm{W}_{\mathrm{o}} \geq \mathrm{W}_{\mathrm{j}}\right) \&\left(\left[\mathrm{~W}_{\mathrm{o}}-\overline{\mathrm{ET}}_{\mathrm{c}} \Delta \mathrm{t}\right] \geq \mathrm{W}_{\mathrm{j}}\right)
\end{array}\right.
\end{aligned}
$$

Note that in Equation (11) earlier, the apparently missing $\Delta \mathrm{t}_{1}$ term for the $\left[\left(\mathrm{W}_{\mathrm{o}} \geq \mathrm{W}_{\mathrm{j}}\right) \&\left(\left[\mathrm{~W}_{\mathrm{o}}-\overline{\mathrm{ET}}_{\mathrm{c}} \Delta \mathrm{t}\right]<\mathrm{W}_{\mathrm{j}}\right)\right]$ case is because the original expression $\left[\overline{\operatorname{ET}}_{\mathrm{c}} \Delta \mathrm{t}_{1}+\overline{\mathrm{ET}}_{\mathrm{c}}\left(\Delta \mathrm{t}-\Delta \mathrm{t}_{1}\right)\right]$ reduces to $\overline{\mathrm{ET}}_{\mathrm{c}} \Delta \mathrm{t}$.

When formulating the relative error in the numerical $\mathrm{ET}_{\mathrm{a}}, \mathrm{S} 12$ noticed that the common $\left(\mathrm{W}_{\mathrm{o}}-\mathrm{W}_{\mathrm{p}}\right)$ term in the analytical Equation (5) earlier and the numerical Equations (6-8) earlier cancelled out. S12 duly asserted that 'relative errors of $\mathrm{ET}_{\mathrm{a}}$ calculated with numerical methods in one time step are independent of the initial soil water storage in the range of soil water stress', and any mention of the initial soil water $\left(\mathrm{W}_{\mathrm{o}}\right)$ is correspondingly absent in the S12 recommendations. However, this supposed independence from $\mathrm{W}_{\mathrm{o}}$ is erroneous as seen from the analytical Equation (10) and numerical Equations (11-13) earlier, where the $\left(\mathrm{W}_{\mathrm{o}}-\mathrm{W}_{\mathrm{p}}\right)$ term need not cancel out while formulating this relative error. This is also illustrated by the example contrast of this reformulationderived relative error (denoted by square markers) between Figure $2 \mathrm{a}\left(\mathrm{W}_{\mathrm{o}}=200 \mathrm{~mm}\right)$ and $2 \mathrm{~b}\left(\mathrm{~W}_{\mathrm{o}}=260 \mathrm{~mm}\right)$ here that use the explicit Euler method, for the lower $\mathrm{ET}_{\mathrm{c}}$ curves. Also, asterisk markers in Figure 2a here plotted using the S12 equations are same as the markers in
Figure 2a by S12; it is evident that the latter plot should actually have been impossible with some $\mathrm{W}_{\mathrm{o}}$ values, because an example $\mathrm{W}_{\mathrm{o}}=260 \mathrm{~mm}$ should reveal missing markers for the lower $\mathrm{ET}_{\mathrm{c}}$ curves as shown by the missing asterisk markers in Figure $2 b$ here. This was missed out on by the $\mathrm{S} 12$ study because its relative error formulation that was independent of $\mathrm{W}_{\mathrm{o}}$ did not reveal any missing markers

In Figure $2 \mathrm{c}-2 \mathrm{~d}$ here, the original field capacity $\left(\mathrm{W}_{\mathrm{f}}\right)$ and wilting point $\left(\mathrm{W}_{\mathrm{p}}\right)$ values for a soil type closer to clay as considered by $\mathrm{S} 12$ are halved towards a soil type closer to loam (Walker, 1989), with $\mathrm{W}_{\mathrm{o}}$ also correspondingly halved; this effectively decreases the soil water storage capacity and hence the water availability for evapotranspiration. The relative error for the explicit Euler method is now seen to decrease after some time step (reflecting the numerical water content value reaching $\mathrm{W}_{\mathrm{p}}$ ) and decreases earlier with an increase in $\mathrm{p}_{\text {std }}(0.55$ for Figure $2 \mathrm{c} v s 0.8$ for Figure $2 \mathrm{~d})$. This contradicts the trend from the equations and Figure 2 of the S12 study where the relative error seemed to monotonically increase with an increasing time step.

The high $\mathrm{p}_{\text {std }}$ value of 0.8 in Figure $2 \mathrm{~d}$ here collapses the relative error value curves for $\mathrm{ET}_{\mathrm{c}}$ of $5-9 \mathrm{~mm} /$ day into 
a single one (not visually discernible) that is distinct from the $\mathrm{ET}_{\mathrm{c}}$ curves of $1-3 \mathrm{~mm} / \mathrm{day}$. This also happens for the example plots for the modified Euler (Figure 2e) and the Heun's third-order methods (Figure 2f) having this same $\mathrm{p}_{\mathrm{std}}$. Note that the usage of the original equations by $\mathrm{S} 12$, where occurrence of soil moisture values outside the valid range were ignored, would have collapsed all the $\mathrm{ET}_{\mathrm{c}}$ curves of $1-9 \mathrm{~mm} /$ day into this single curve. Hence, the reformulated equations accurately and better resolve the behaviour in relative error for such high $\mathrm{p}_{\text {std }}$ values.

A comparison between Figure $2 b-2 d$ here shows the relative error curves starting out steeper for lower soil water storage capacities (i.e. lower $\mathrm{W}_{\mathrm{f}}$ and $\mathrm{W}_{\mathrm{p}}$ ) and higher $\mathrm{p}_{\text {std }}$ values. This aspect was not highlighted by S12; although the properties of the specific crop-soil composite used were specified, the absence of a caveat about the validity of those results regarding relative error for that specific composite clearly gave an erroneous impression that those results and consequent recommendations were valid for all crop-soil composites.

Using the same relative error threshold of $5 \%$ by $\mathrm{S} 12$ and a time step of 1 day, Figure $2 \mathrm{c}-2 \mathrm{~d}$ here show that the explicit Euler method can only be used for these crop-soil composites if $\mathrm{ET}_{\mathrm{c}}$ is some respective specific value less than $5 \mathrm{~mm} /$ day. This contrasts with the recommendation 'A' earlier by S12 that this method can be used for any $\mathrm{ET}_{\mathrm{c}}$ for a 1-day time step. Similarly, for a 2-day time step, the explicit Euler method is supposedly invalid if $\mathrm{ET}_{\mathrm{c}}$ is above $5 \mathrm{~mm} /$ day as per the recommendation ' $\mathrm{B}$ ' above by S12, but Figure $2 \mathrm{c}-2 \mathrm{~d}$ here show this method becoming invalid above some lower respective specific value of $\mathrm{ET}_{\mathrm{c}}$ between 3 and $5 \mathrm{~mm} /$ day and dependent on the crop-soil composite and its initial condition.

Similarly, for the modified Euler method, the respective recommendations ' $\mathrm{C}$ ' and ' $\mathrm{D}$ ' earlier by $\mathrm{S} 12$ state that the method can be respectively used for any $\mathrm{ET}_{\mathrm{c}}$ in case of a 1-week time step and for an $\mathrm{ET}_{\mathrm{c}}$ of $5 \mathrm{~mm} /$ day or less in case of a 10-day time step. However, for the specific cropsoil composite and initial condition in Figure 2e here, this method can be used only when $\mathrm{ET}_{\mathrm{c}}$ is below some respective specific value between 1 and $3 \mathrm{~mm} /$ day for both time steps. Finally, the recommendation ' $E$ ' earlier by $\mathrm{S} 12$ states that the Heun's $3^{\text {rd }}$-order method can be used for up to a 15-day time step for any $\mathrm{ET}_{\mathrm{c}}$. However, this recommendation becomes invalid when $\mathrm{ET}_{\mathrm{c}}$ is above $3 \mathrm{~mm} /$ day for the specific crop-soil composite and initial condition in Figure $2 \mathrm{f}$ here (note that its $x$-axis extends out to 15 days).

\section{CONSIDERING THE RELATIVE ERROR IN CUMULATIVE $\mathrm{ET}_{\mathrm{A}}$}

The cumulated $\mathrm{ET}_{\mathrm{a}}$ at the end of the crop season (or harvest) is more relevant to the crop yield than the $\mathrm{ET}_{\mathrm{a}}$ over any single time step and is a common metric used in drought early warning systems (e.g., Senay and Verdin, 2002). In providing recommendations, S12 considered only single time-step simulations, with the largest time step being 15 days. For considering multiple time-step simulations, a simulation period of 60 days (approximately 2 months) is used here.

Crop seasons are typically quite longer than 60 days, with some individual crop growth phases possibly spanning up to 60 days or even more (Allen et al., 1998). The assumption 3 earlier of a constant $\mathrm{ET}_{\mathrm{c}}$ even over multiple time steps as shown in Figure 3 by S12 is now relaxed here to allow a different $\mathrm{ET}_{\mathrm{c}}$ for each time step in a simulation. This allows a piecewise linear increase/decrease of $\mathrm{ET}_{\mathrm{c}}$ over a simulation and correspondingly a characterization of linearly increasing/decreasing portions of the crop coefficient curve. Any desired temporal combination of these portions with constant $\mathrm{ET}_{\mathrm{c}}$ portions enables an assessment of the relative error in the cumulated $\mathrm{ET}_{\mathrm{a}}$ over the relevant crop phenology simulation.

For the specific crop-soil composite used by S12, the 60-day evolution of the relative error in cumulated $\mathrm{ET}_{\mathrm{a}}$ using the reformulated equations for the explicit Euler method is shown here for the following: a constant $\mathrm{ET}_{\mathrm{c}}$ at $5 \mathrm{~mm} /$ day appearing in the $\mathrm{S} 12$ recommendations (Figure 3a), a constant $\mathrm{ET}_{\mathrm{c}}$ at constant upper limit of $9 \mathrm{~mm} /$ day considered by S12 (Figure $3 \mathrm{~b}$ ), an $\mathrm{ET}_{\mathrm{c}}$ linearly increasing from $1 \mathrm{~mm} /$ day to $9 \mathrm{~mm} /$ day during the simulation (Figure 3c), and an $\mathrm{ET}_{\mathrm{c}}$ linearly decreasing from $9 \mathrm{~mm} /$ day to $1 \mathrm{~mm} /$ day (Figure $3 \mathrm{~d}$ ). Figures $3 \mathrm{a}-3 \mathrm{~d}$ show that each relative error is actually near or below $5 \%$ at 60 days for a time step of up to 10 days with a projected decreasing trend beyond 60 days, meaning that the relative error for their piecewise linear combination over time should also be within $5 \%$ at 60 days and beyond. Also note the relative error at 60 days for an $\mathrm{ET}_{\mathrm{c}}$ of $9 \mathrm{~mm} /$ day is actually lower than that for an $\mathrm{ET}_{\mathrm{c}}$ of $5 \mathrm{~mm} / \mathrm{day}$, due to a faster decrease in its relative error over time (Figures 3a-3b).

\section{SUMMARY}

The S12 assumptions included (i) ignoring water input resulting in a root zone that eventually dries out as with rain-fed crops in water-scarce regions, (ii) constant $\mathrm{ET}_{\mathrm{c}}$ over multiple time steps and (iii) deep groundwater implying negligible soil water flux through the bottom of root zone. This latter flux is significant in many regions (e.g. Schmid and Hanson, 2009; Schmid et al., 2009). The assumption of no water input is specifically restrictive against a practical application of its equations for estimating $\mathrm{ET}_{\mathrm{a}}$. This essentially means that this model is inapplicable when water input becomes available. The S12 analytical and numerical formulations of $\mathrm{ET}_{\mathrm{a}}$ over limited soil water ranges without accounting for transition 
between the ranges restrict their applicability and accuracy. Also, the erroneous impression of a general validity of the S12 recommendations could have been avoided through exercising more rigour in either checking results for other crop-soil composites or specifying relevant caveats.

Although conforming to the S12 assumptions, a reformulation of its equations here towards applicability over the entire soil water range reveals a dependence of the relative error in numerical $\mathrm{ET}_{\mathrm{a}}$ on the initial soil water. This relative error is also shown to be greatly dependent on the crop-soil composite. The consequently more complicated actual nature of this relative error now shows that crop and soil properties and the initial soil water also have to be considered in making recommendations regarding an appropriate numerical method.

Finally, any such recommendation can also consider the simulation setup and goal. For example, instead of considering the error in numerical $\mathrm{ET}_{\mathrm{a}}$ at every time step, one can alternatively consider the error in cumulative $\mathrm{ET}_{\mathrm{a}}$ for calculating crop yield.

\section{ACKNOWLEDGEMENTS}

We gratefully acknowledge the support from NASA's Applied Science Program Solicitation NNH08ZDA001N-
DECISIONS (PI: Verdin). We also appreciate the useful review comments and suggestions provided by Editor Malcolm Anderson, two anonymous reviewers and USGS internal reviewer Amy McNally.

\section{REFERENCES}

Allen RG, Pereira LS, Raes D, Smith M. 1998. Crop evapotranspirationGuidelines for computing crop water requirements. FAO Irrigation and drainage paper 56. Food and Agriculture Organization of the United Nations: Rome, Italy. ISBN 92-5-104219-5. Online at http://www.fao. org/docrep/X0490E/X0490E00.htm

Schmid W, Hanson RT. 2009. Appendix 1, supplemental informationmodifications to modflow-2000 packages and processes. In Groundwater Availability of the Central Valley Aquifer, California, U.S. Geol. Surv. Prof. Pap. 1776, Faunt CC (ed.). U.S. Geol. Surv.: Reston, VA; 213-225. Online at http://pubs.usgs.gov/pp/1766/PP_1766.pdf

Schmid W, King JP, Maddock III TM. 2009. Conjunctive Surface-Water/ Ground-Water Model in the Southern Rincon Valley using MODFLOW-2005 with the Farm Process, prepared for the Elephant Butte Irrigation District, Las Cruces, NM. New Mexico Water Resources Research Institute Completion Report No. 350. Online at http://www.wrri.nmsu.edu/publish/techrpt/tr350/tr350.pdf

Senay G, Verdin J. 2002. Evaluating the performance of a crop water balance model in estimating regional crop production. Proceedings of the Pecora 15 Symposium, Denver, CO. http://earlywarning.usgs.gov/ adds/pubs/Pecora15\%20CropWaterBalance\%20GSandJV.pdf

Walker WR. 1989. Guidelines for Designing and Evaluating Surface Water Irrigation systems. FAO Irrigation and drainage paper 45 . Food and Agriculture Organization of the United Nations: Rome, Italy. ISBN 92-5102879-6. Online at http://www.fao.org/docrep/T0231E/T0231E00.htm 